of the buttress cliffs of Suil Liath at an altitude of $2,000 \mathrm{ft}$. The time taken on the whole of this return flight was $1 \mathrm{~min} .45 \mathrm{sec}$.

I measured the distance on the 1 -in. Ordnance Survey map between the points of the eagle's rising and landing and found it to be exactly $3 \frac{1}{2}$ miles. This makes the rate of flight 120 miles an hour with a net gain in altitude of $1,000 \mathrm{ft}$. There was a very slight cross wind from the west. The peregrines were left far behind on the downward sweep. We have, therefore, a timed flight in a straight line (in plan) between two known points, the flight being made with, presumably, some urge towards maximum speed.

Brae House,

Dundonnell,

Wester Ross. July 31 .

\section{Causes of Suppression of Crossing-Over in Males of} Drosophila melanogaster

ThE possibility of artificially inducing crossingover in males of Drosophila melanogaster ${ }^{1}$ has enabled us to attempt by genetic methods the study of the direct causes of the suppression of crossing-over in Drosophila males. Investigations on the effect of inversions on crossing-over evoked by subjecting Drosophila males to X-ray treatment may apparently throw light on this problem.

The experiments carried out by me in the winter of 1933-34 have shown that inversions in males throughout regions of chromosomes not touched by them, inhibit crossing-over in a much feebler degree than in the case of females, and this means that inversions in spermatogenesis cause a smaller conflict of forces' than in ovogenesis.

These data point to a diminution of forces of attraction between homologous loci of chromosomes in spermatogenesis, which does not affect the degree of proximity of homologous chromosomes indispensable to crossing-over, nor does it gainsay in principle the possibility of crossing-over : it is necessary only to X-ray the males when, as also with females, a closer junction of the long autosome's central parts during conjugation is brought about and the potential possibilities of crossing-over in the male are thereby accomplished.

A feebler effect of the forces of attraction between homologous loci of the chromosome ought not to hinder chromosome conjugation by the regions of attachment of the spindle fibre. Here, most likely, crossing-over normally occurs in males. This is Darlington's opinion ${ }^{2}$. However, this point of view is not confirmed genetically, as the regions here indicated are genetically inert and crossing-over in the long two-armed autosomes of $D$. melanogaster is usually accomplished in each of the limbs, and is in this case always a double one.

It is noteworthy that these data and deductions fully coincide with cytological data of Koller and Townson ${ }^{3}$, which deal with the same subject.

A detailed account of this work will be published shortly.

Institute of Experimental Biology,

HeINRICh FrIESEN.

Moscow.

July 20.

${ }^{1}$ Friesen, H., Science, 78, No. 2031; 1933 ; and Friesen, H., Biol.

3 Proc. Roy. Soc. Edin., '53, 130-146 ; 1932-33.

\section{Inland Water Survey}

The leading article in NATURE of August 4 and Admiral Sir Perey Douglas's letter in the following issue referring to it deal with a subject of very real importance.

That the public supply of good water to every individual of the whole of the inhabitants of Great Britain should be the first consideration of a Government would no doubt be accepted by most people without much argument, for it is the basis of the good health of the community. But this is by no means the case, singular as it may seem. We have a completely interlinked and co-ordinated supply system for electricity for the whole country but in water supply the Victorian ways persist. Almost complete individualism is still the practice both within and without the Ministry. Any development, however remotely akin to that of electricity, is anathema. Thus it is that in some districts you can turn on the light but not the water.

In any development for a national water supply, the first great work would be the ascertainment of all our water resources, a hydrogeological survey, and it is to be hoped that the Minister of Health will give thorough consideration to the request of Admiral Douglas's deputation for this.

For myself, being interested in the whole subject, I cannot help but wonder even if we got our survey, unless something more is to follow we should not again be held up, possessing all the information but no power to use it or make others do so. So many definite recommendations to deal with this part of the question have been made by commissions and committees in the past, for example, the interim report in 1920 of the Board of Trade Committee presided over by Sir John Snell, that it ought not to bo necessary to quote, requote and add any further reasons in support. Of works of urgent public im. portance involving in their carrying out much employment, the bringing up to date of our water supply is the first. Alan Chorlton.

Le Zoute.

\section{Free Alumina in Soils}

IN the literature of soil science, the assumption is frequently made that, because a soil or product of rock weathering yields, when chemically analysed by acid digestion and fusion methods, a high proportion of alumina, it must therefore contain at least a part of its aluminous components in the uncombined state. That this is not necessarily the case has been indicated $^{1}$ by the application of an alizarin adsorption method, devised by me, to a series of laterites, bauxites, kaolins, subsoils and surface soils, including some that are red in colour, collected mainly in the West Indies. The alizarin method depends on the fact (apparently first discovered in 1928 by Schmelev) that gibbsite $\left(\mathrm{Al}_{2} \mathrm{O}_{3} \cdot 3 \mathrm{H}_{2} \mathrm{O}\right)$ and diaspore $\left(\mathrm{Al}_{2} \mathrm{O}_{3} \cdot \mathrm{H}_{2} \mathrm{O}\right.$ ) after heating to temperatures around $800^{\circ} \mathrm{C}$., but not before heating, develop the ability to adsorb in suitable circumstances appreciable quantities of alizarin. The amount adsorbed may be determined colorimetrically by extracting the stained washed material with acidified sodium oxalate solution.

The procedure was afterwards applied in a study of rock-weathering in British Guiana. ${ }^{2}$. Some of the materials tested were nearly identical with those previously exhaustively examined chemically and petrographically by the late Sir John Harrison ${ }^{3}$. Comparison between the results obtained and 